\title{
The procedure of selecting the best construction equipment by the set of its quantitative characteristics
}

\author{
Petr Romanov ${ }^{1}$, and Irina Romanova ${ }^{2, *}$ \\ ${ }^{1}$ State Educational Institution of Higher Education of Moscow Region State University of Humanities \\ and Social Studies, Department of machine science, 30, Zelyonaya street, Moscow Region, Kolomna, \\ 140410, Russian Federation \\ ${ }^{2}$ Moscow State University of Civil Engineering, Yaroslavskoe shosse, 26, Moscow, 129337, Russia
}

\begin{abstract}
Today's construction projects are highly mechanized. That's why selection of right equipment has always been a key factor in the success of any construction project. This decision is typically made by comparison of equipment feature, productivity, capacity and cost. The article describes the approach to selecting the best set of construction equipment from the available options by the set of its quantitative characteristics. It is proposed to carry out the evaluation of options and selection of the best option based on the method of spectral analysis. The article presents the results of the selection of the most appropriate floor screed conveyor for purchasing by construction company using the specified method.
\end{abstract}

\section{Introduction}

Screeds, made according to different technologies, are usually applied in industrial, commercial and residential buildings for leveling the surface of the underlying layer, giving a specified slope, distribution of loads for heat and sound insulation layers, providing normalized heat absorption of floors. Screeds can also be used to enclose heating elements, electrical wiring or different pipelines [1]. Traditional cement-sand screeds of stiff consistency are obtained by the «moist» method. Its main disadvantages are its higher average density, the possibility of a leakage of excess water into downstream areas, long period of curing before laying the flooring, the appearance of cracks during drying, and high laboriousness $[2,3]$. The cement-sand screed, produced by alternative technology «semi-dry screed»- is devoid of these disadvantages. A semi-dry mortar contains the minimum amount of water required only for hydration of cement that reduces the evaporation of unbound water and the associated formation of pores, and thus, increases the strength of screed, almost nonexistent drying shrinkage and significantly reduced drying time [4]. According to recommendations [5], for traditional cement-sand screeds up to a thickness of $40 \mathrm{~mm}$ should be given a drying rate of $1 \mathrm{~mm} /$ day, followed by an increasing

Corresponding author: nirs-isa@mail.ru 
time of $0.5 \mathrm{~mm}$ per day for the remaining thickness. Eg. $75 \mathrm{~mm}$ screed will take 110 days to dry to a suitable level in good conditions with the temperature maintained at $20^{\circ} \mathrm{C}$ and a relative humidity of $55 \%$. At the same time semi-dry screed will take only 4 days to dry in similar conditions [6].

To facilitate and accelerate the laying of cement-sand mixture, in the construction industry was introduced a new technology - mechanical screed, which allows to mechanize some operations and significantly reduce the duration and amount of works. Works mechanized way implies a high degree of automatization and the use of special construction equipment for the creating screed mixes, delivering them to the place of installation, smoothing and polishing of the surface. The floor screed conveyor is used for automatically creating of the cement-sand mortar and pumping it on the high pressure screed pump hoses to the location of the screed. The smoothing machine is used to smooth and compact bonded and special screed [7-9].

In modern conditions large construction organizations often put building objects (apartment buildings, underground parking's, etc.) into operation without finishing, this work is done by private construction organizations (small and medium), as well as individual entrepreneurs, specializing in complex finishing works or on some kinds of works, including semi-dry floor screed. These construction works require different types of equipment and machineries having their own level of application. Selection of right equipment has always been a key factor in the success of any construction project [10].

In this context, the task of selecting the most appropriate set of construction equipment from the available options is highly challenging task and consists of several sub-tasks [1114]:

comparison of options of technological equipment to the execution of the same kind of work according to the set quality indicators and selection of the most efficient of them (the problem of comparative evaluation of technical level of technical systems executing the same tasks in the same range of characteristics (indicators));

selection of a rational option of the set of technological equipment for realization of all construction works of the many possible options to equip the construction organization (multi-criteria decision task).

The paper proposes a solution of the first subproblem, especially actual for small construction organization (individual entrepreneur) specializing in one or just a few types of construction work, for example, semi-dry floor screeding in a residential buildings.

\section{Experimental section}

If only quantitative characteristics of the technological equipment are known, the most simple and effective method of solving the problem of rational selecting is the method of spectral analysis. The essence of the method is as follows $[11,12,14]$.

There are $n$ compare options of floor screed conveyors (SC) $\left(S C_{i}, i=\overline{1, n}\right)$, which can be assigned to a number of technical characteristics $X_{j}, j=\overline{1, m}$, that determine the preference of a floor screed conveyor. The preference of the floor screed conveyor SC from the standpoint of one of the characteristics $X_{j}$ can be defined by indicator $x_{i j}$, has a certain physical meaning. It is considered that all characteristics initially are equivalent: $W_{i}^{(0)}=1, V_{j}^{(0)}=1$, where $W_{i}^{(0)}, V_{j}^{(0)}$ - weight values at zero iteration for the floor screed conveyors and their characteristics, respectively.

It is necessary to build the array floor screed conveyors from the available set of different models, manufactured in different countries, by preference, taking into account the 
set quality indicators $x_{i j}, i=\overline{1, n}, j=\overline{1, m}$. Then, make a choice of the most preferred to buy floor screed conveyor.

The problem is solved by implementation of spectral analysis iterative procedure:

$$
\begin{aligned}
& W_{i}^{(k)}=\left(\sum_{j=1}^{m} V_{j}^{(k-1)} \tilde{x}_{i j}\right) /\left(\max _{i} \sum_{j=1}^{m} V_{j}^{(k-1)} \tilde{x}_{i j}\right) \\
& V_{j}^{(k)}=\left(\sum_{i=1}^{n} W_{i}^{(k-1)} \tilde{x}_{i j}\right) /\left(\max _{j} \sum_{i=1}^{n} W_{i}^{(k-1)} \tilde{x}_{i j}\right)
\end{aligned}
$$

where $n$ is the number of floor screed conveyors;

$m$ - the number of technical characteristics;

$k=\overline{1, K}$-the iteration number in the iterative process (if $k \rightarrow \infty$, then $W_{i}, V_{j} \rightarrow$ const); $W_{i}^{(k)}, V_{j}^{(k)}$ - weight values at $k$-iteration for the floor screed conveyors and their characteristics, respectively;

$$
\tilde{x}_{i j}=\left\{\begin{array}{l}
\frac{x_{i j}}{\max \left\{x_{i j}\right\}}, \text { if the increase } x_{i j} \text { leads the enhancement of properties SC; } \\
\frac{\min \left\{x_{i j}\right\}}{x_{i j}}, \text { if the decrease } x_{i j} \text { leads the enhancement of properties SC. }
\end{array}\right.
$$

It is suggested the following algorithm for solving the problem of selecting the most appropriate floor screed conveyor:

1. To build a calculated table in the form of Table 1 (the direction of the calculations is

\begin{tabular}{|c|c|c|c|c|c|c|c|c|c|}
\hline & $V_{l}$ & $\ldots$ & $V_{j}$ & $\ldots$ & $V_{m}$ & $W_{i}^{(0)}$ & $W_{i}^{(I)}$ & $W_{i}^{(2)}$ & $W_{i}^{(3)}$ \\
\hline$W_{l}$ & $\tilde{x}_{11}$ & $\ldots$ & $\tilde{x}_{1 j}$ & $\cdots$ & $\tilde{x}_{1 m}$ & 1 & $W_{l}^{(1)}$ & $\ldots$ & $W_{l}^{(3)}$ \\
\hline$\ldots$ & $\ldots$ & $\ldots$ & $\ldots$ & $\ldots$ & $\ldots$ & $\ldots$ & $\ldots$ & $\ldots$ & $\ldots$ \\
\hline$W_{i}$ & $\tilde{x}_{i 1}$ & $\ldots$ & $\tilde{x}_{i j}$ & $\cdots$ & $\tilde{x}_{i m}$ & 1 & $W_{i}^{(I)}$ & $\cdots$ & $W_{i}^{(3)}$ \\
\hline$\ldots$ & $\ldots$ & $\ldots$ & $\ldots$ & $\ldots$ & $\ldots$ & $\ldots$ & $\ldots$ & $\cdots$ & $\ldots$ \\
\hline$W_{n}$ & $\tilde{x}_{n 1}$ & $\ldots$ & $\tilde{x}_{n j}$ & $\ldots$ & $\tilde{x}_{n m}$ & 1 & $W_{n}^{(1)}$ & $\ldots$ & $W_{n}^{(3)}$ \\
\hline$V_{j}^{(0)}$ & 1 & $\ldots$ & 1 & $\ldots$ & 1 & & & & \\
\hline$V_{j}^{(I)}$ & $\cdots$ & $\cdots$ & $\cdots$ & $\ldots$ & $\cdots$ & & & & \\
\hline$V_{j}^{(2)}$ & $V_{I}^{(2)}$ & $\ldots$ & $V_{j}^{(2)}$ & $\ldots$ & $V_{m}^{(2)}$ & & & & \\
\hline$V_{j}^{(3)}$ & $\ldots$ & $\ldots$ & $\ldots$ & $\ldots$ & $\ldots$ & $\Delta$ & & & \\
\hline$V_{j}^{(4)}$ & $V_{l}^{(4)}$ & $\ldots$ & $V_{j}^{(4)}$ & $\ldots$ & $V_{m}{ }^{(4)}$ & & & & \\
\hline
\end{tabular}
shown by arrows).

Table 1. Intermediate calculations form 
2. To calculate the normalized matrix $\tilde{x}_{i j}, i=\overline{1, n}, j=\overline{1, m}$. Enter all the values $\tilde{x}_{i j}$ in Table 1.

3. For $k=1$ to calculate by the Eq. (1) values $W_{i}^{(1)}$, assuming $V_{j}^{(0)}=1$ and taking values of $\tilde{x}_{i j}, i=\overline{1, n}, j=\overline{1, m}$ obtained in the previous step of the algorithm. Enter all the values $W_{i}^{(l)}$ in the Table 1.

4. For $k=2$ to calculate $V_{j}^{(2)}$ by the Eq. (2) based on the data obtained in the previous step of the algorithm. Enter all the values $V_{j}^{(2)}$ in the Table 1 .

5. To continue the calculation of the values of $W_{i}^{(k)}$ for odd iterations and $V_{j}^{(k)}$ for even iterations as indicated in steps 3 and 4 of the algorithm. The calculation was carried out as long as the value of $W_{i}^{(k)}$ and $V_{j}^{(k)}$ will not accept the weight values obtained at the previous iteration. A replay of the weight values usually starts at $\mathrm{k} \geq 7$.

6. Further filling of the Table 1 is carried out after settlement $W_{i}^{(k)}$ and $V_{j}^{(k)}$ by the Eq. (1) and (2), but the calculation starts with finding the values $V_{j}^{(l)}$ assuming $W_{i}^{(0)}=1$, and further by the algorithm. $i=\overline{1, n}$.

7. Based on the obtained values of $W_{i}^{(k)}$ to build the array of floor screed conveyors $\mathrm{SC}_{i}$,

8. To determine the best floor screed conveyor $\mathrm{SC}_{i}$. The best option is the one which have the highest value weight $W_{i}^{(k)}$.

According to [13-15], it is no need to use all the quantitative technical characteristics of this equipment to select the best option of technological equipment, it is enough to select only the main ones that have an impact on the process operation and results of this work. In addition, it is advisable not to use correlated features, if it is possible to allocate them. This does not change the result of selecting the best equipment, but reduces the dimensionality of the task.

Main technical specifications of floor screed conveyors include: useful capacity; pressure vessel capacity; maximum aggregate size; filling height; delivery range distance, wide; delivery range distance, high; power of the compressor; engine power; dimensions (size $\mathrm{L}^{*} \mathrm{~W} * \mathrm{H}$ and weight); sound level; approval for road use. Moreover, the maximum aggregate size, dimensions, filling height, sound level and approval for road use are about the same on all models single class and are not decisive in the selection of floor screed conveyor. Also before the comparison it is necessary to exclude correlated technical specifications: the power of the compressor is associated to the engine power and delivery range distance - to pressure vessel capacity.

The selecting of the most appropriate floor screed conveyor for purchasing by construction company was made from six the most popular models: BrinkmannEstrich Boy 450 (Germany), BrinkmannEstrich Boy 450BS (Germany), PutzmeisterMixokret M 740 DH (Germany), PutzmeisterMixokret M 750 DHBS (Germany), LudgerGlaap\& Fritz BrinkmannMixMan D4 (Germany), CO-243 (Russia).

Main quantitative characteristics of floor screed conveyors selected for comparison, are presented in Table $2[15,16]$.

For calculations has been used a program previously written in Delphi 7 [14]. The number of iterations was taken equal to ten $(\mathrm{k}=10)$. 
Table 2.Main quantitative characteristics of floor screed conveyors selected for comparison

\begin{tabular}{|c|c|c|c|c|c|c|}
\hline \multirow[b]{2}{*}{$\begin{array}{l}\text { Floor screed conveyor } \\
\text { model }\end{array}$} & \multicolumn{6}{|c|}{ Quantitative characteristics } \\
\hline & 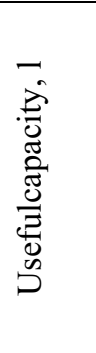 & 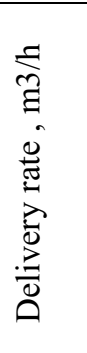 & 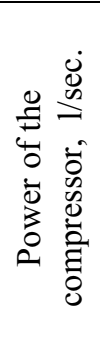 & 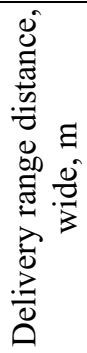 & 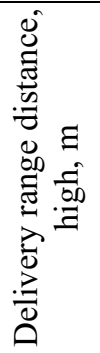 & 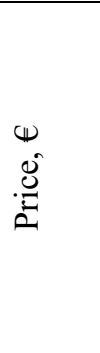 \\
\hline $\begin{array}{l}\text { BrinkmannEstrich Boy } \\
450\end{array}$ & 200 & 3.8 & 70 & 180 & 90 & 35000 \\
\hline $\begin{array}{c}\text { BrinkmannEstrich Boy } \\
\text { 450BS }\end{array}$ & 200 & 5.0 & 70 & 180 & 90 & 42700 \\
\hline $\begin{array}{c}\text { PutzmeisterMixokret M } \\
740 \mathrm{DH}\end{array}$ & 200 & 4.0 & 83 & 200 & 150 & 36200 \\
\hline $\begin{array}{c}\text { PutzmeisterMixokret M } \\
750 \text { DHBS }\end{array}$ & 200 & 5.0 & 83 & 200 & 150 & 49800 \\
\hline $\begin{array}{c}\text { LudgerGlaap\& Fritz } \\
\text { BrinkmannMixMan D4 }\end{array}$ & 200 & 4.3 & 43 & 205 & 95 & 25000 \\
\hline $\mathrm{CO}-243$ & 260 & 4.0 & 70 & 200 & 70 & 19500 \\
\hline
\end{tabular}

\section{Results section}

Initially, calculations are made for six floor screed conveyors and five technical specifications (excluding the cost of equipment). As a result of calculations was obtained the array of options (the values of assessment are given in the brackets):

1 -PutzmeisterMixokret M 750 DHBS (1);

2 -PutzmeisterMixokret M 740 DH (0.9564);

3 - CO-243 (0.8722);

4 -BrinkmannEstrich Boy 450BS (0.8705);

5 -BrinkmannEstrich Boy 450 (0.8182);

6 -LudgerGlaap\& Fritz BrinkmannMixMan D4 (0.8057);

and the array of characteristics:

1 - Delivery range distance, wide, $\mathrm{m}(1)$;

2 - Delivery rate, $\mathrm{m}^{3} / \mathrm{h}(0.9208)$;

3 - Power of the compressor, $1 / \mathrm{h}(0.8981)$;

4 - Useful capacity, 1 (0.8510);

5 - Delivery range distance, high, $\mathrm{m}(0.7670)$.

Thus, the most important characteristic is «Delivery range distance, wide», and the best option is PutzmeisterMixokret M 750 DHBS. However, in a market economy the cost of the technical system or equipment is crucial in the choice. That's why calculations also were made for the same models of floor screed conveyors with regard to their cost.

As a result of calculations was obtained the array of options (the values of assessment are given in the brackets):

1 -PutzmeisterMixokret M 750 DHBS (1);

2 -PutzmeisterMixokret M 740 DH (0.9803); 
3 - CO-243 (0.9696);

4 -BrinkmannEstrich Boy 450BS (0.8879);

5 -LudgerGlaap\& Fritz BrinkmannMixMan D4 (0.8745);

6 -BrinkmannEstrich Boy 450 (0.8539).

and the array of characteristics:

1 - Delivery range distance, wide, $\mathrm{m}(1)$;

2 - Delivery rate, $\mathrm{m}^{3} / \mathrm{h}(0.9180)$;

3 - Power of the compressor, $1 / \mathrm{h}(0.8936)$;

4 - Useful capacity, $1(0.8530)$;

5 - Delivery range distance, high, $\mathrm{m}(0.7633)$;

6 - Price, $€$

\section{Discussion section}

It is appreciable, that the cost occupies the last place in order of importance among the characteristics and not have a significant effect on the ranging of options (swapped only the last two options). Thus, despite the high cost, the best option is PutzmeisterMixokret M 750 DHBS.

The advantage of the proposed method is the lack of subjective evaluations in the process of selecting source data and calculations. The disadvantages include: the lack of consideration of the initial importance of the characteristics and applicability of the method only for the characteristics defined unambiguous quantitative indicators.

It is possible to set the importance of each characteristic beforehand and to consider it in the calculations by the method of spectral analysis. But in this case, there is a need to engage experts to specify the importance of characteristics, i.e. the importance of the characteristics to some extent be a subjective value.

\section{Conclusions}

The proposed technique can be applied for selection of the most appropriate set of technological equipment from the available options on the basis of quantitative characteristics also in other sectors of the economy.

\section{References}

1. Codes: SP 29.13330.2011: The floor. (technical regulatory material, Moscow, 2011)

2. K. Popov, M. Kaddo, Constr. Comp. Mat., 2, 20-23 (2006)

3. K. Popov, M. Kaddo, Techn. Concr., 12, 1-7 (2007)

4. J. Ingham, Geomaterials Under the Microscope: A Colour Guide ( Academic Press, London, 2011)

5. Technical advice: TR 137-03. Technical advice for use of specialized dry finishing mixes for interior and exterior works in the construction of new buildings, reconstruction and repair (technical regulatory material, Moscow, 2011)

6. J. Bergmans , P. Nielsen , R. Snellings , K. Broos , Constr. Build. Mater ., 111 , 9 - 14 (2016)

7. M. Hambacha,H. Möllerb,T. Neumannc,D. Volkmera,Comp. B: Eng., 90, 465-470 (2016)

8. C.J. Middleton,J.M.W. Brownjohn, Eng. Str.,32, 337-352 (2010) 
9. N. Williamson, Adv. Concr.Techn., 4, 3-38 (2003)

10. M.Warisa,M.S.Liewa,M.F.Khamidib,A.Idrusc, Int. J.Sust. BuiltEnviron, 3, 96-110 (2014)

11. I. Kafiev, P. Romanov, Bull. Bashkir Univ., 2(26), 83-86 (2013)

12. I. Kafiev, P. Romanov, I. Romanova, Bull. Bashkir Univ., 3(35), 48-52 (2015)

13. I. Kafiev, P. Romanov, I. Romanova, Bull. Bashkir Univ., 1(33), 82-90 (2015)

14. P. Romanov, I. Kirjakov, 3 Int. scient.-pract. conf. Techn., politics and Econ., 86-94 (2016)

15. URL: http://www.directindustry.com/industrial-manufacturer/floor-screed-conveyor80953.html

16. URL: $\underline{\text { http://www.stpbrinkmann.ru/production/pnevmonagnetateli }}$ 